\title{
ASSESSMENT
}

\section{An Online Training Program to Enhance Novice Researchers' Knowledge and Skills}

\author{
Lynn Gilbertson, Jeannine Rowe, Yeongmin Kim, University of Wisconsin-Whitewater \\ Catherine W. M. Chan, University of Wisconsin-Eau Claire \\ Naomi Schemm, Michael Unhoch, University of Wisconsin-Whitewater
}

\begin{abstract}
This article describes a multidisciplinary, asynchronous, 10-hour online training program for undergraduates enrolled in a mentored research apprentice program, addressing communication skills, knowledge of the research process, information literacy, and research ethics. A pretest-posttest survey was completed to assess students' perceived gains $(n=130)$ in knowledge and skills. A survey was also administered to faculty mentors $(n=50)$ to assess observations regarding students' gains. Results revealed significant perceived gains in all four content areas $(p<0.001)$ with no significant differences across disciplines. The findings suggest that the training content and format were successful in providing participants with foundational research knowledge and skills. Mentors' observations support the student findings and identify gains in discipline-specific skills. Implications for undergraduate research programs are discussed.
\end{abstract}

Keywords: early undergraduate research, interdisciplinary, remote learning, research ethics, research skills

doi: 10.18833/spur/4/4/4

An extensive body of research documents the value of undergraduate research programs (Kuh 2008), which are programs designed for students with little to no research experience, and typically focus on enrolling first-year and second-year students. Undergraduate research programs (URPs), including research apprenticeships in which students work on faculty mentored projects, are valuable because they contribute to higher retention rates and reduction in equity gaps (Chan, Bhattacharyya, and Meisel
2018, Finley and McNair 2013; Ishiyama and Hopkins 2003). Although there are a variety of URPs within colleges and universities across the United States, the University of Michigan's award-winning Undergraduate Research Opportunity Program serves as a foundational model for research apprenticeships and related programming (Gregerman 2009). Guided by this model, the University of Wisconsin Whitewater URP developed the Research Apprenticeship Program (RAP).

\section{Research Apprentice Program (RAP)}

Developed and piloted from 2009 to 2011 and institutionalized in 2012, RAP is a mentored research apprenticeship program that offers first-year, second-year, and transfer students with little to no research knowledge or experience hourly pay for engaging in faculty-led research. Students across disciplines, ranging from the humanities to STEM, can work up to 125 hours over an academic year on the faculty-led research project. The program was created to increase participation in mentored research by expanding applied research opportunities and models for students in professional degree programs, particularly in business and education. Additionally, RAP was created in response to repeated requests by students who had little research experience and wanted applied research opportunities (Chan et al. 2018).

Although RAP was initially met with excitement, there was reluctance among some mentors to involve novice research students in projects. This reluctance stemmed from concerns regarding early-stage students' limited research knowledge and skills, and preference for more experienced upper-level students. To better understand these concerns and formulate a plan for addressing them, 
RAP administrators held numerous focus groups with mentors. One outcome of the focus groups was that RAP should include a research training component. Mentors indicated that they would appreciate having some systematic support providing basic training of foundational research skills to RAP students. In response to mentors' suggestions, RAP administrators began the process of developing an educational training for the program's students.

Examination of "entering research" curricula resulted in the realization that existing curricula were typically designed for small cohorts (12-15 students) and were often embedded in credit-bearing courses or workshops across 10 - to 15 -week sessions. The Colloquium for the Undergraduate Research Opportunity Program (UROP) at Florida State University is one example of a creditbearing course for beginning student researchers (Center for Undergraduate Research and Academic Engagement n.d.). A team from the University of Wisconsin-Madison also developed a curriculum for supporting undergraduate mentees (Branchaw, Butz, and Smith 2019). Further investigation resulted in identification of face-to-face and synchronous workshop offerings on various research topics that are tailored to discipline specific knowledge and skills. For example, the University of Michigan UROP (n.d.) offers skill-building workshops. Given that RAP typically supports 80 students each year, a small cohort model was not feasible. Moreover, given the range of academic disciplines involved in RAP as well as the limited staffing support for RAP, a discipline-specific training model was not practical.

To accommodate a large number of students with varying schedules, program administrators deliberately chose to develop an online, asynchronous training program that includes content relevant to a wide range of disciplines. The result is the RAP Online Training, which was introduced to students in 2018.

\section{RAP Online Training}

The RAP Online Training is an online, 10-hour, asynchronous training hosted on the university's online learning management system (LMS). The training includes educational content in four areas and includes a variety of activities such as discussions, applied exercises, and quizzes. This format provides easy access to the content, due to students' familiarity with the university's LMS, and accommodates students' schedules.

Students are enrolled in the training after they are hired in RAP. Students have 60 days to complete the training and are paid up to 10 hours (of the allotted 125 hours) to do so. Mentors have access to the training through the LMS so that they can observe and have context to support their students' completion if warranted. The training is managed by a URP administrator and research librarian, and both provide individualized feedback on the training module activities.

To reinforce the importance of the training, students who fail to complete the training within 60 days are not paid for their work in RAP until the training is completed. The university's human resources department confirmed that this method of nonpayment complies with the state's at-will work laws. Students who fail to complete the RAP Online Training are given opportunities to make up the missed deadline. When the training is complete, students receive payment for the training as well as for any unpaid hours that they completed while working on the faculty-mentored research project during the noncompliance period. Students who fail to complete the training altogether are dismissed from RAP for noncompliance.

\section{Training Content}

The RAP Online Training includes content designed to enhance students' skills and knowledge in four content areas: communication skills, knowledge of the research process, information literacy, and research ethics. Content is delivered across six online modules. These four content areas were selected because they reflect the general research skills that apply across disciplines and support the basic knowledge and skills required for early-stage investigators (Sadler and McKinney 2010; Gebbie et al. 2008; Pfund et al. 2013; Handelsman and Handelsman 2005).

\section{Module 1}

The first module provides an overview of RAP and includes content on communication when working as part of a research team. A central feature of this module is educating students on the importance of communication with their mentors. As part of this module, students view educational materials and complete activities in which they need to engage with their mentors. A main requirement for students is to demonstrate an understanding of shared expectations. These facets mirror research environments in which principal investigators often lead and guide research and creative endeavors. Anecdotal and empirical evidence suggests that an understanding of mutual expectations is foundational for a mentored relationship (Pfund et al. 2013; Handelsman and Handelsman 2005).

In addition to educational content and activities central to Module 1, students also complete a pretest survey that asks them to rate their comfort levels in the four training content areas (i.e., communication skills, knowledge of the research process, information literacy, and research ethics). The survey is re-administered to students at the completion of the training in module six.

\section{Module 2}

Module 2 focuses on the research process. It contains materials and activities that are designed to enhance students' 
understanding and undertaking of research. The content includes a summary of the research process from question and investigation to analysis and dissemination. The content included herein attempts to break down perceptions of intimidation regarding the research process, which is often a barrier to students in terms of conducting research or belonging in higher education. This is especially true for underrepresented minority students (Strayhorn 2019, 53, 94).

\section{Module 3}

Module 3 focuses on information literacy. This module includes educational materials on how to use the university library and wider literary sources to conduct a literature and article review. The module describes the purposes and organization of a literature review. Students practice tasks such as identifying effective search keywords from a research question, reading and understanding scholarly articles, and identifying the purpose and parts of academic citations. To reinforce information literacy and demonstrate an understanding of it as an important part of the research process, students meet with the university librarian and complete a variety of applied activities.

\section{Module 4}

Module 4 provides an overview of research methods. Included in this module is an introduction to different approaches to inquiry such as qualitative, quantitative, and mixed-method approaches, as well as different types of research designs such as exploratory research, experimental research, surveys, and observational studies. An important element of this module is that students are required to meet with their mentors and identify where their designated research projects lie within the range of methods and continuum of designs. As with previous modules, students complete a variety of activities to reinforce and understand research methods.

\section{Module 5}

Module 5 covers research ethics. It includes content on the responsible conduct of research both in terms of conducting research, particularly with human subjects, and disseminating research findings. The latter focuses on presenting materials and avoiding plagiarism. As part of this module, students are required to complete the social, behavioral, and education (SBE) training included in the university's Collaborative Institutional Training Initiative course (CITI n.d.). In addition to completing the SBE CITI training, students also complete an exercise on writing in their own words as a way to reinforce what does and does not constitute plagiarism.

\section{Module 6}

The last module highlights additional undergraduate research experience opportunities after RAP eligibility ends. Included within this module is information about programs offered by the university's URP that may support students' continued interests in mentored research. External opportunities within the undergraduate research community are also provided. The only required activity within this module is completion of the posttest survey.

To assess the merits of the RAP Online Training, a pretestposttest survey of students' perceived gains in research knowledge and skills was conducted. In addition, a survey of mentors' perceptions regarding their student's growth in the areas of research knowledge and skills was also conducted. It was hypothesized that students who completed the RAP Online Training would report perceived gains in their research knowledge and skills. It was also hypothesized that mentors would report perceived gains in their students' research knowledge and skills.

\section{Methods}

An exploratory study was conducted using the data collected as part of the RAP Online Training. Students' pretest and posttest data were used to examine their perceived gains in research knowledge and skills. Additionally, data from the faculty mentors, which was collected after individual students completed the RAP Online Training and research apprentice program, was used to examine mentors' perceptions regarding students' gains in research knowledge and skills. The study was approved by the university's Institutional Review Board.

\section{Sample}

Students. The study included data for students aged 18 years and older who were enrolled in RAP between fall 2018 and spring 2020 and completed the RAP Online Training as well as the pretest and posttest knowledge and skills survey. A total of 166 students completed the pretest, and 130 completed the posttest. The analysis includes the 130 students who completed both the pretest and posttest.

Mentors. The study included data from undergraduate research mentors who supported students between fall 2018 and spring 2020 and voluntarily completed the mentor survey. A total of 50 out of 118 mentors completed the survey.

\section{Measures}

Students' Perception of Research Knowledge and Skills. To assess students' gain in their communication skills, information literacy, knowledge of the research process, and knowledge of research ethics, they completed a 10-item survey. The survey, which was developed by RAP administrators, asked students to rate their level of comfort using a five-point scale $(0=$ not at all comfortable to $4=$ extremely comfortable) on the four content areas. As shown in Table 1, two items correspond to communication skills, five items correspond to information literacy, two items correspond to the knowledge of the research process, 
TABLE 1. Questionnaire Items to Assess Students' Perceived Research Knowledge and Skills

\begin{tabular}{|l|l|}
\hline Items (How comfortable are you ...) & Content areas \\
\hline $\begin{array}{l}\text { Approaching faculty and staff } \\
\text { Working with faculty and staff }\end{array}$ & Communication skills \\
\hline $\begin{array}{l}\text { Locating library resources } \\
\text { Identifying reliable sources of information } \\
\text { Finding valid sources of information } \\
\text { Citing the work of others } \\
\text { Using the library search tools }\end{array}$ & Information literacy \\
\hline $\begin{array}{l}\text { Describing the research process } \\
\text { Identifying different types of research methodologies }\end{array}$ & Knowledge of the research process \\
\hline Recognizing when research needs approval to be conducted & Knowledge of research ethics \\
\hline
\end{tabular}

and one item corresponds to the knowledge of research ethics. The average of the item scores is used to measure each of the four content areas (ranging from 0 to 4 ). The pretest and posttest surveys were administered electronically as part of the RAP Online Training, prior to starting the training and at the completion of the training.

Mentors' Perception of Student Growth. Mentors completed a survey designed by the RAP administrators to understand the mentors' perceived experience with the RAP program. One of the questions asked mentors to indicate areas in which they observed their students' growth. Particularly, mentors were asked to check all that apply to the growth of their student mentees regarding the following skills and knowledge areas: communication skills, research process, information literacy, research ethics, and field- or discipline-specific skills. The mentor survey was administered after students completed the RAP Online Training and the mentored research apprentice program.

\section{Data Analysis Procedures}

Paired-samples $t$-tests were used to examine students' perceived growth in research knowledge and skills. Tests were conducted to assess gains on each of the four online training content areas and overall. Additionally, ANOVA tests were used to evaluate whether the observed changes in perceived gains differed among students across academic disciplines. Finally, descriptive statistics were used to report the number of mentors who observed perceived gains in their mentees on research knowledge and skills.

\section{Results}

\section{Demographic Characteristics of Sample Students}

Table 2 presents the observed characteristics of the students in the sample $(n=130)$ as well as the characteristics of the students enrolled at the university during the twoyear observation period. In terms of the study sample, the majority are female (63.1 percent), White (86.9 percent), and traditional (i.e., age 25 or younger and unmarried;
(97.7 percent). One-third of the sample students are also first-generation college students ( 32.3 percent). The sample also consists largely of first- and second-year students (67 percent). In terms of academic discipline, the majority of the sample is enrolled in a STEM-related major (54.6 percent), followed by students enrolled in social sciences (37.7 percent), and humanities (6.9 percent). As shown in Table 2, the student sample typically mirrors that of the larger campus population.

\section{Students'Perceived Gains on Research Knowledge and Skills}

To examine the effects of the RAP Online Training on students' perceived gains in research knowledge and skills, students' pretest to posttest scores were compared on each of the four online training content areas and overall. The results are presented in Table 3 . In terms of perceived gains in communication skills, a significant increase in students' pretest score $(M=2.99, S D=0.79)$ to posttest score $(M=3.42, S D=0.67)$ was observed $(p<0.001)$. A significant increase in information literacy gains (pretest $M=2.74, S D=0.61$; posttest $M=3.22, S D=0.56$ ) was also observed $(p<0.001)$. Gains in knowledge of the research process was observed from pretest $(M=1.86, S D$ $=1.04)$ to posttest $(M=3.03, S D=0.72)$, and this increase was significant $(p<0.001)$. Students' perceptions of their gains in research ethics from pretest $(M=2.18, S D=0.95)$ to posttest $(M=2.89, S D=0.81)$ was also significant ( $p$ $<0.001)$. Overall, students' perceived gains in research knowledge and skills were significant $(p<0.001)$

When comparing the size of the improvement among the four dimensions of research knowledge and skills, the change in students' knowledge of the research process was greater than the other dimensions. Before the RAP Online Training, students indicated that they were not comfortable with describing the research process or identifying different research methodologies $(M=1.86, S D=1.04)$. However, after the RAP Online Training, students reported that they were far more comfortable in their knowledge of 
TABLE 2. Demographic Characteristics of Sample and Campus Population

\begin{tabular}{|c|c|c|c|}
\hline & $\begin{array}{l}\text { Training enrollment } \\
2018-2020(n=130)\end{array}$ & $\begin{array}{l}\text { Undergraduate enrollment } \\
2018-2019^{\mathrm{a}} \\
(\mathrm{N}=13,425)\end{array}$ & $\begin{array}{l}\text { Undergraduate enrollment } \\
2019-2020^{\mathrm{a}} \\
(\mathrm{N}=12,581)\end{array}$ \\
\hline \multicolumn{4}{|l|}{ Gender } \\
\hline Male & $48(36.9 \%)$ & $49.5 \%$ & $50.4 \%$ \\
\hline Female & $82(63.1 \%)$ & $50.5 \%$ & $49.6 \%$ \\
\hline \multicolumn{4}{|l|}{ Race/ethnicity } \\
\hline White & $113(86.9 \%)$ & $80.4 \%$ & $80.9 \%$ \\
\hline Black & $5(3.9 \%)$ & $3.9 \%$ & $4 \%$ \\
\hline Other & $12(9.2 \%)$ & $15.7 \%$ & $15.1 \%$ \\
\hline \multicolumn{4}{|l|}{ Academic status } \\
\hline Traditional & $127(97.7 \%)$ & $89 \%$ & $89.1 \%$ \\
\hline Nontraditional & $3(2.3 \%)$ & $11 \%$ & $10.9 \%$ \\
\hline \multicolumn{4}{|l|}{ First generation } \\
\hline Non-first gen & $88(67.7 \%)$ & $61 \%$ & $65 \%$ \\
\hline First gen & $42(32.3 \%)$ & $39 \%$ & $35 \%$ \\
\hline \multicolumn{4}{|l|}{ Academic level $^{\mathrm{b}}$} \\
\hline First year & $24(18.5 \%)$ & $21 \%$ & $21 \%$ \\
\hline Second year & $63(48.5 \%)$ & $27 \%$ & $27 \%$ \\
\hline Third year & $38(29.2 \%)$ & $25 \%$ & $24 \%$ \\
\hline Fourth year & $5(3.8 \%)$ & $29 \%$ & $30 \%$ \\
\hline \multicolumn{4}{|c|}{ Academic discipline ${ }^{c}$} \\
\hline Humanities & $9(6.9 \%)$ & $17 \%$ & $17 \%$ \\
\hline Social sciences & $49(37.7 \%)$ & $45 \%$ & $45 \%$ \\
\hline STEM & $71(54.6 \%)$ & $37 \%$ & $38 \%$ \\
\hline Others & $1(0.8 \%)$ & $1 \%$ & $0 \%$ \\
\hline
\end{tabular}

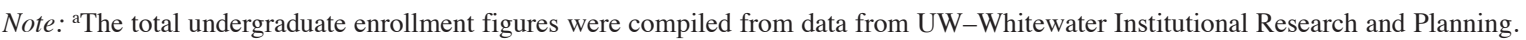

bUndergraduate enrollment percentages add up to more than 100 because of rounding and academic-level tracking based on total credits earned rather than years on campus.

"Humanities" include art, communication, English, film studies, history, journalism, liberal arts, liberal studies, and music. "Social sciences" include art education, business, communication sciences and disorders, criminology, early child education, economics, elementary education, entrepreneurship, general management, geography, marketing, political science, psychology, social work, sociology, and special education. "STEM" includes accounting, biology, chemistry, computer science, environmental science, finance, information technology, mathematics, media arts and game development, and physics. "Others" include associate of arts and science and undeclared.

the research process $(M=3.03, S D=0.72)$. The Cohen's $d$ for this dimension was higher than $1(d=1.08)$, which suggests a strong effect (Rubin and Babbie 2017). The effect sizes for communication skills, information literacy, and research ethics show a medium to strong effect ( 0.60 , 0.87 , and 0.65 , respectively).

\section{Differences in Gains by Academic Discipline}

In terms of differences in gains by academic discipline, none were found. As shown in Table 4, pretest and posttest scores on communication skills, information literacy, knowledge of the research process, research ethics, and overall were similar for students in the humanities, social sciences, and STEM fields $(p>0.05)$.

\section{Mentors' Perspective}

Table 5 shows the descriptive results of mentors' $(n=50)$ perspectives. Approximately three-quarters ( 72 percent) of mentors observed growth in students' knowledge of the research process. Almost half indicated growth in students' communication skills (46 percent) and in field or discipline-specific skills (46 percent). Just under half of the mentors (44 percent) observed growth in inquiry and analysis skills. When asked about information literacy and research ethics, observations regarding growth in these skills were lower ( 36 percent and 22 percent, respectively). The findings regarding mentors' perceptions mirror those of the students. This is especially true for knowledge of the research process, in which the effect size for students 
TABLE 3. Changes of Students' Comfort in Research Knowledge and Skills from Pretests to Posttests

\begin{tabular}{|l|c|c|c|c|c|c|}
\hline & \multicolumn{2}{|c|}{ Pretest } & \multicolumn{2}{c|}{ Posttest } & \multirow{2}{*}{$p$-value } & \multirow{2}{*}{$\begin{array}{c}\text { Effect Size } \\
\text { (Cohen's } d \text { ) }\end{array}$} \\
\cline { 2 - 6 } & Mean & SD & Mean & SD & & \\
\cline { 1 - 6 } $\begin{array}{l}\text { Overall research knowledge and } \\
\text { skills (all items) }\end{array}$ & 2.56 & 0.60 & 3.19 & 0.51 & $p<0.001$ & 1.08 \\
\hline Communication skills & 2.99 & 0.79 & 3.42 & 0.67 & $p<0.001$ & 0.60 \\
\hline Information literacy & 2.74 & 0.61 & 3.22 & 0.56 & $p<0.001$ & 0.87 \\
\hline Knowledge of the research process & 1.86 & 1.04 & 3.03 & 0.72 & $p<0.001$ & 1.02 \\
\hline Research ethics & 2.18 & 0.95 & 2.89 & 0.81 & $p<0.001$ & 0.65 \\
\hline
\end{tabular}

Note: Scores can range 0 to 4 , with 4 indicating the highest level of comfort. $n=130$.

TABLE 4. Students' Comfort in Research Knowledge and Skills by Academic Disciplines

\begin{tabular}{|c|c|c|c|c|c|c|}
\hline & \multicolumn{2}{|c|}{ Pretest } & \multicolumn{2}{|c|}{ Posttest } & \multirow{2}{*}{$\begin{array}{l}\text { Mean of Score } \\
\text { Changes }\end{array}$} & \multirow{2}{*}{$\begin{array}{l}\text { ANOVA test for } \\
\text { the difference } \\
\text { in changes }\end{array}$} \\
\hline & Mean & SD & Mean & SD & & \\
\hline \multicolumn{7}{|c|}{ Overall research knowledge and skills (all items) } \\
\hline Humanities & 2.82 & 0.71 & 3.44 & 0.39 & 0.62 & \multirow{3}{*}{$p=0.160$} \\
\hline Social sciences & 2.47 & 0.57 & 3.22 & 0.50 & 0.75 & \\
\hline STEM & 2.60 & 0.60 & 3.14 & 0.53 & 0.54 & \\
\hline \multicolumn{7}{|c|}{ Communication skills } \\
\hline Humanities & 3.28 & 0.57 & 3.61 & 0.42 & 0.33 & \multirow{3}{*}{$p=0.906$} \\
\hline Social sciences & 3.02 & 0.84 & 3.47 & 0.72 & 0.45 & \\
\hline STEM & 2.94 & 0.79 & 3.37 & 0.65 & 0.42 & \\
\hline \multicolumn{7}{|c|}{ Information literacy } \\
\hline Humanities & 2.98 & 0.63 & 3.58 & 0.46 & 0.6 & \multirow{3}{*}{$p=0.127$} \\
\hline Social sciences & 2.65 & 0.61 & 3.24 & 0.53 & 0.59 & \\
\hline STEM & 2.78 & 0.60 & 3.17 & 0.58 & 0.39 & \\
\hline \multicolumn{7}{|c|}{ Knowledge of the research process } \\
\hline Humanities & 2.11 & 1.22 & 3.11 & 0.70 & 1 & \multirow{3}{*}{$p=0.207$} \\
\hline Social sciences & 1.71 & 0.97 & 3.11 & 0.71 & 1.4 & \\
\hline STEM & 1.95 & 1.06 & 2.98 & 0.73 & 1.02 & \\
\hline \multicolumn{7}{|l|}{ Research ethics } \\
\hline Humanities & 2.56 & 1.01 & 3.11 & 0.78 & 0.56 & \multirow{3}{*}{$p=0.294$} \\
\hline Social sciences & 1.94 & 0.90 & 2.84 & 0.90 & 0.90 & \\
\hline STEM & 2.31 & 0.95 & 2.90 & 0.76 & 0.59 & \\
\hline
\end{tabular}

Note: Scores can range 0 to 4 , with 4 indicating the highest level of comfort.

is strong (Cohen's $d=1.08$ ) and reported by the majority of mentors $(n=36 ; 72$ percent $)$.

\section{Discussion}

Findings from this study suggest that the 10-hour, asynchronous, RAP Online Training contributes to students' perceived gains in communication skills, knowledge of the research process, information literacy, and research ethics skills. Of particular importance is the finding regarding growth in understanding the research process, which was

38 Scholarship and Practice of Undergraduate Research reinforced with both the student and mentor survey data. This finding is of value because students in RAP have little to no research experience. Effectively, the RAP Online training program and research apprentice portion of the program provide a platform for training a new cohort of scientists and affording mentors time to focus on discipline-specific skills and knowledge.

The findings regarding research ethics are also of interest. Students reported relatively low levels of comfort with 
TABLE 5. Mentors' Observations of Growth in Students' Knowledge and Skills

\begin{tabular}{|l|c|c|}
\hline Area & Count & Percentage \\
\hline Knowledge of the research process & 36 & $72 \%$ \\
\hline Communication & 23 & $46 \%$ \\
\hline Field or discipline-specific skill & 23 & $46 \%$ \\
\hline Inquiry and analysis & 22 & $44 \%$ \\
\hline Information literacy & 18 & $36 \%$ \\
\hline Research ethics & 11 & $22 \%$ \\
\hline
\end{tabular}

Note: $n=50$. Mentors were asked to "select all that apply"; therefore, count values add up to more than 50 .

ethics on the pretest measure. Although the findings document growth in this area, the increase is modest. Given that ethics is a central feature in all research endeavors, future programming might benefit from enhancing curriculum and training in this area. Within the RAP Online Training, the ethics curriculum focused heavily on social and behavioral sciences - as evidenced by completing the SBE portion of CITI. Potential revision might include salient multidisciplinary examples that apply ethics to all majors.

The insignificant differences in gains by academic disciplines suggest that the RAP Online Training is appropriate for all majors, which was an original goal of the program. This finding may also be of interest to other URP programs who are seeking a refined way to train a range of students across disciplines. Additionally, these findings coupled with the overall findings regarding significant improvement in perceived gains on communication skills, information literacy, knowledge of the research process, and research ethics suggest that the training content, format, and length/dose was successful in providing multidisciplinary novice research students with foundational research skills.

By including a description of the RAP Online Training Program, other institutions and URPs can replicate and revise to meet their needs. The RAP Online Training format may be especially valuable for institutions that are pivoting toward online learning while offering mentored research opportunities.

Although this study makes a valuable contribution to undergraduate research and its literature base, there are some limitations that temper the findings. The main limitations relate to the methods employed. The study is a pretest-posttest survey design, which tends to be viewed as a weak design. The study sample sizes are also relatively small ( $n=130$ students; $n=50$ mentors). The student sample, although reflective of campus demographics as depicted in Table 2, contained less than 33 percent of students self-identifying as underrepresented minority students or first-generation college students. If RAP, a mentored research program for novice researchers, is designed to recruit and support underrepresented minority and firstgeneration students, it may be valuable for the institution to target these two student populations more intentionally. It is possible that the findings in this study may look different with a more diverse sample. As such, these findings can only be viewed as preliminary and are not generalizable. To strengthen the findings, future research that employs a more rigorous design with a larger number of diverse students and mentors is needed. Another limitation relates to the measures, which were designed specifically for this study and may have limited validity and reliability. It is possible that asking students about their "comfort" in the areas of communication skills, information literacy, knowledge of the research process, and research ethics is not an accurate reflection of perceived gains. It is also possible that the measure used to assess mentors' perceptions of students gains in knowledge and skills is not an accurate reflection of their impressions. Future research would benefit from using standardized measures to assess perceived gains.

Finally, the timing of mentors' completion of the measure may have influenced the results. Mentors were asked to complete the measure after students completed RAP, which again involves students working on the mentor's research project. It is possible that some students completed the RAP Online Training Program earlier in the semester-well before they completed working on the mentor's project. In these instances, it is possible that mentors' observations were based more on their students' involvement on their research projects and less on the content included in the RAP Online Training modules. If the goal is to assess the value of the RAP Online Training Program, future research should require mentors to complete the perception measure immediately after their students complete the online program.

\section{Conclusion}

Despite the limitations, the study makes a valuable contribution to the scholarship of undergraduate research. To the authors' knowledge, few asynchronous online trainings 
that include curriculum to teach students research skills and knowledge exist. As such, this study is timely and much needed. The RAP Online Training described here can provide a model for other institutions and undergraduate research communities to utilize and replicate. Further, this study provides preliminary evidence regarding the value of an asynchronous online training to enhance skills and knowledge. These findings reinforce the value of complementary online training to support undergraduate research students and address the needs of mentors.

\section{References}

Branchaw, Janet L., Amanda R. Butz, and Amber Smith. 2019. Entering Research: A Curriculum to Support Undergraduate \& Graduate Research Trainees. New York: Macmillan Higher Education.

Center for Undergraduate Research and Engagement, Florida State University. n.d. "The Colloquium." Accessed June 15, 2021. https://cre.fsu.edu/undergradresearch/urop/colloquium

Chan, Catherine W. M., Prajukti Bhattacharyya, and Seth Meisel. 2018. "A Model for Successful Cross-Campus Collaboration for Engaging Potentially At-Risk Students in Mentored Undergraduate Research Early in Their College Career." Scholarship and Practice of Undergraduate Research 1(3): 48-56. doi: 10.18833/ spur/1/3/13

CITI Program. n.d. "Human Subjects Research: HSR.” Accessed June 15, 2021. https://about.citiprogram.org/en/series/humansubjects-research-hsr/

Finley, Ashley, and Tia McNair. 2013. Assessing Underserved Students' Engagement in High-Impact Practices. Washington, DC: Association of American Colleges and Universities.

Gebbie, Kristine M., Benjamin Mason Meier, Suzanne Bakken, Olveen Carrasquillo, Allan Formicola, Sally W. Aboelela, Sherry Glied, et al. 2008. "Training for Interdisciplinary Health Research: Defining the Required Competencies." Journal of Allied Health 37(2): 65-70.

Gregerman, Sandra R. 2009. "Filling the Gap: The Role of Undergraduate Research in Student Retention and Academic Success." In Broadening Participation in Undergraduate Research: Fostering Excellence and Enhancing the Impact, edited by Mary K. Boyd and Jodi L. Wesemann, 245-256. Washington, DC: Council on Undergraduate Research.

Handelsman, Jo, and Hilary Handelsman. 2005. Entering Mentoring: A Seminar to Train a New Generation of Scientists. Madison: Board of Regents of the University of Wisconsin System. https://www.hhmi.org/sites/default/files/Educational\%20Materials/Lab\%20Management/entering_mentoring.pdf

Ishiyama, John T., and Valerie M. Hopkins. 2003. "Assessing the Impact of a Graduate School Preparation Program on First-Generation, Low-Income College Students at a Public Liberal Arts University." Journal of College Student Retention: Research, Theory and Practice 4: 393-405. doi: 10.2190/cb17uenx-n064-u1hq

Kuh, George D. 2008. High-Impact Educational Practices: What They Are, Who Has Access to Them, and Why They Matter. Washington, DC: Association of American Colleges and Universities.

40 Scholarship and Practice of Undergraduate Research
Pfund, Christine, Stephanie House, Kimberly Spencer, Pamela Asquith, Paula Carney, Kristyn S. Masters, Richard McGee, et al. 2013. "A Research Mentor Training Curriculum for Clinical and Translational Researchers." Clinical and Translational Science 6(1): 26-33. doi: 10.1111/cts.12009

Rubin, Allen, and Earl R. Babbie. 2017. Research Methods for Social Work. 9th ed. Boston: Cengage Learning.

Sadler, Troy D., and Lyle McKinney. 2010. "Scientific Research for Undergraduate Students: A Review of the Literature." Journal of College Science Teaching 39(5): 43-49.

Strayhorn, Terrell L. 2019. College Students' Sense of Belonging: A Key to Educational Success for All Students. New York: Routledge.

Undergraduate Research Opportunity Program (UROP), University of Michigan. n.d. "Skill-Building Workshops." Accessed June 15, 2021. https://lsa.umich.edu/urop/current-urop-students/ urop-resources/skill-building-workshops.html

\section{Lynn Gilbertson}

University of Wisconsin-Whitewater,

gilbertl@uww.edu

Lynn Gilbertson is an associate professor in the Department of Communication Sciences and Disorders at University of Wisconsin-Whitewater $(U W-W)$. She serves as an undergraduate research mentor, encouraging students to integrate science and technology to support hearing health and preserve communication. Her recent administrative roles as department chair and associate director for undergraduate research sparked a passion for improving recruitment and retention of underrepresented students through engagement in high-impact practices.

Jeannine M. Rowe is a professor of social work, social gerontologist, and former associate director for Undergraduate Research Programs at UW-W. She is an applied researcher in health and aging, and mentors multidisciplinary undergraduate students to advance knowledge in these areas. She has a special interest in growing and diversifying the workforce in health and aging.

Yeongmin Kim is associate professor of social work at $U W-W$. His research interest involves child support policy and child-care policy. He has substantial experience in program evaluation using quantitative research methods. He teaches research methods and social welfare policy for undergraduate and graduate social work students.

Catherine W. M. Chan is executive director of the Office of Research and Sponsored Programs at the University of Wisconsin-Eau Claire. Prior to this appointment, she was a professor at $U W$-W. For 10 years, she worked in $U W$-W's URP to broaden participation in mentored research, especially by students from minoritized backgrounds. She is interested in better integrating student learning and undergraduate research. She serves as a CUR councilor in the CUR Chemistry Division. 
Naomi Schemm is the reference and instruction librarian for the College of Business \& Economics at UW-W. As part of this role she, with other librarians, helped develop the RAP training module focused on information literacy and provided student feedback on the relevant tasks.
Michael Unhoch was a master's student in the Counselor Education Program at UW-W. He held a graduate assistantship position as RAP coordinator from 2018 to 2021, connecting faculty mentors to student researchers.

\section{CUR's Excellence in Mentoring book}

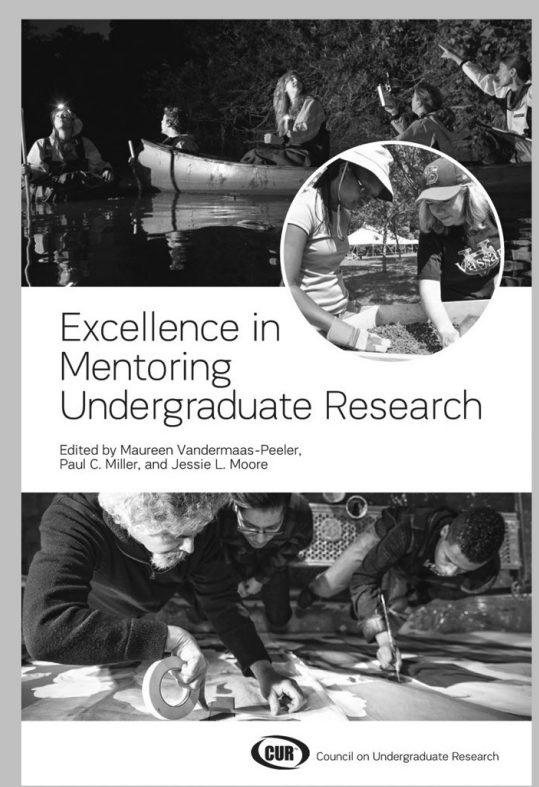

Excellence in Mentoring Undergraduate Research incorporates diverse perspectives on mentoring undergraduate research, including work from scholars at many different types of academic institutions in Australia, Canada, the United Kingdom, and the United States. It strives to extend the conversation on mentoring undergraduate research to enable scholars in all disciplines and a variety of institutional contexts to critically examine mentoring practices and the role of mentored undergraduate research in higher education.

To order, visit the CUR Bookstore (https://bit.ly/CURbkstore) 